\title{
DIOGENES SYNDROME: A PROSPECTIVE OBSERVATIONAL STUDY
}

\author{
J.-C. Monfort ${ }^{1,2}$, E. Devouche ${ }^{3}$, C. Wong 4 , I. Pean ${ }^{5}$, L. Hugonot-Diener ${ }^{6,7}$
}

\begin{abstract}
Objectives: This prospective study was designed to look for the most appropriate appellation, clinical symptoms, and underlying associated diseases, and to investigate a possible central etiology. Design and Participants: This prospective observational study involved 50 subjects aged 50-93 years, living in their home in Paris, and consecutively notified to the community authorities due to risks (fire) or nuisances (stench, parasites, hoarding). Clinical symptoms, associated diagnoses, cognitive capacity and life events during childhood were assessed. Results: Hoarding is both the most frequent and the least alerting symptom. Six clinical types cover both medical and social situations that lead to notifications of risk and nuisances to the authorities. Almost half of the situations remained social as no diseases were found to be associated with the Diogenes syndrome. A traumatic life event during childhood could be a risk factor for all Diogenes syndromes although it is most often present among subjects without an associated disease. Conclusions: Our results are in favor of maintaining the appellation "Diogenes syndrome", which embraces the entirety of the diverse situations reported to the authorities, social services and medical networks. These situations require time and a coordinated investigation by a medico-social team, as subjects with Diogenes syndrome do not always have an associated disease.
\end{abstract}

Key words: Diogenes syndrome, Hoarding, Self-neglect, Squalor, Childhood.

\section{Introduction}

Clark was the first to coin the appellation "Diogenes syndrome" (DS). He described thirty elderly patients known to the community authorities because they lived in a state of domestic squalor and gross self-neglect (1). Several patients hoarded useless objects. The size of the collection reduced the living space in $20 \%$ of the cases. One third of the patients repeatedly declined offers of help, while some of them accepted food from friendly neighbors. Surprisingly, a high intelligence quotient and an absence of poverty were found, although such patients had already been reported as "beggar hoarders" by Dupré in 1925 (2). Clark chose the name of the philosopher Diogenes of Sinope, known to live in a jar without any possessions and opposed to hoarding and collections (3). Thus, Clark's reference to Diogenes remained incomprehensible for a long time (4-6). Many

1. Centre Hospitalier Sainte-Anne, 1 rue Cabanis, 75014 Paris, France; 2. Sorbonne Paris Cité, Université Paris Descartes, France; 3. Université Paris Descartes, Laboratoire Psychopathologie et Processus de Santé (EA 4057), France; 4. Cabinet libéral, 27 rue Blomet, 75015 Paris, France; 5. CLIC Paris Emeraude Ouest, 24 Boulevard de Grenelle, 75015 Paris, France; 6. CMRR Paris Sud-Hôpital BrocaAPHP, 54/55 rue Pascal, 75013 Paris, France; 7. Memory-Geriatric Network for Paris south and center, 169 rue St Jacques, 75006 Paris, France

Corresponding Author: Laurence Hugonot-Diener, CMRR Paris Sud-Hôpital BrocaAPHP, 54/55 rue Pascal, 75013 Paris. Tel: 00331440836 36. Cell: 00336851348 69. Email: laurence.hugonot-diener@aphp.fr

Received February 17, 2017

Accepted for publication February 22, 2017 other appellations have been used in clinical practice such as senile breakdown (7-9), hoarding $(10,11)$, self-neglect (12-14) and squalor (15). In fact, Diogenes syndrome is still controversial. Recent papers pointed out the lack of a consensual nosology (16) and the need for a transnosographic approach (17).

Our first retrospective study used operational criteria in order to identify Diogenes syndrome and assess its frequency in Paris (18). The mandatory criterion was an absence of a request in spite of a need for everything (19). Other clinical symptoms were considered as three additional criteria: an unusual relationship with objects (hoarding), an unusual relationship with one's body (selfneglect) and an unusual relationship with people (social withdrawal) (18). The results revealed different clinical types, an absence of any disease in some cases and a history of traumatism during childhood which led us to design a prospective study. The objectives of the present study were to look for the most appropriate appellation, the frequency of clinical symptoms, the underlying associated diseases, and to investigate a possible central etiology. 


\section{Methods}

The prospective design of this observational study involved a cohort of 50 older subjects, living in their own home, consecutively notified to the community authorities due to risks (fire), or nuisances (stench, parasites, hoarding) and who suffered from gross selfneglect or worrying social withdrawal.

An interview was conducted by one of the three clinicians (JCM, LHD and CW). Semi-structured interviews were impracticable with these subjects who are prone to refusing to open their door and often identified as "reluctant to any assistance" (19). As in other "current care studies" and in order to respect ethics and retain our usual approach, this interview was interactive and non-structured. The criteria used to include subjects with Diogenes syndrome and to describe the type of situation were those used in our previous study (one mandatory criterion and at least one additional criterion). ICD-10 criteria were used to diagnose mental disorders and associated diseases. A French version of the Mini Mental State (MMS) (20), the Global Deterioration Scale (GDS) (21), and the Fronto-temporal Behavioral Scale (FBS) (22) were used to assess cognitive functions and behavioral problems. The subjects' life histories were collected during this interview, with a draft genogram to back up oral statements whenever possible.

Analyses were performed with Stata 12 for Windows. Logistic regression was used to estimate the odds ratios (ORs) and Wald 95\% confidence intervals (CI). The ORs were adjusted for age at the time of the study, gender, and the number of children.

Our study was approved by the consultative committee of the French Research Ministry as "usual care research" (approval by CCTIRS N09642bis), which resulted in no requirement for CPP approval. The data remained anonymous with, consequently, no need for CNIL approval.

\section{Results}

Fifty subjects were consecutively included: verbal consent and assent were obtained for all subjects, but written consent was obtained for only seven of them.

\section{Socio-demographic characteristics}

The mean age was 78 years \pm 9 (range 50-93). The male/ female ratio was $24 / 26$. One-third had children. Five out of 50 were living with someone else and 23 were helped by a reliable caregiver. Six out of 50 had previously been subjected to mandatory cleaning with an obligation to reduce hoarding by the legal authorities. Former occupations were similar to those in the Paris general population. However, the number of former unemployed Diogenes subjects, 3 out 50 i.e. $6 \%$, was three times lower than in the Paris general population (18\%).

\section{Alerting symptoms and clinical typology of Diogenes syndromes}

The reasons for home visits are shown in Figure 1. One Diogenes situation was discovered during a fire alert. The most frequent alerting symptoms in the building were the smell (32 cases) and parasites (13 cases).

Figure 1

Reasons for home visits. Smell or parasites were the most frequent alerting symptoms in the building

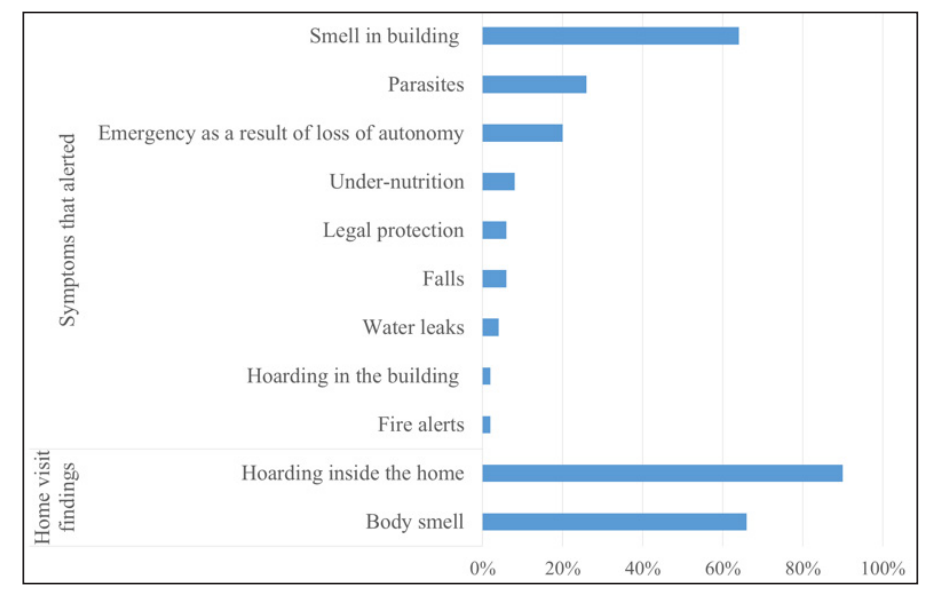

Surprisingly, hoarding was an alerting symptom for only one case, although it was the most common symptom observed during home visits.

Hoarding was an alerting symptom for only one case. Nevertheless, hoarding was observed in 45 of the 50 homes. Six clinical types of Diogenes syndrome were observed. One-third of subjects had full-blown Diogenes syndrome (hoarding, self-neglect and social withdrawal). Two-thirds had a partial syndrome with only one or two additional criteria (Table 1).

\section{Associated diseases}

Twenty-three subjects out of $50(46 \%)$ had no associated diseases, whereas $27(54 \%)$ had an associated disease with two main categories of diagnosis according to ICD-10.

Twelve Diogenes subjects had psychotic disorders: schizophrenia (F20; $\mathrm{n}=2$ ), schizotypal disorder (F21; $\mathrm{n}$ $=1$ ), delusion disorder (F22; $\mathrm{n}=8$ ) and other psychotic disorder (F28; $\mathrm{n}=1)$.

Twenty Diogenes subjects had dementia: Alzheimer's disease (G30.9; $\mathrm{n}=3$ ), fronto-temporal dementia (G31.0; $\mathrm{n}=13$ ), vascular dementia (F01.5; $\mathrm{n}=3$ ), and mixed dementia $(n=1)$. No Lewy body dementia was found.

Five Diogenes subjects had a psychotic disorder in adulthood associated with dementia in old age. 
Table 1

Clinical types of Diogenes syndrome. Six types were observed (the mandatory criterion was the absence of a request in spite of needs for everything)

\begin{tabular}{|c|c|c|c|c|c|c|}
\hline \multirow{2}{*}{$\begin{array}{l}\text { Number of additional criteria } \\
\text { Type }\end{array}$} & \multirow{2}{*}{$\begin{array}{c}\text { Three criteria } \\
\text { Type } 1\end{array}$} & \multicolumn{3}{|c|}{ Two criteria } & \multicolumn{2}{|c|}{ One criterion } \\
\hline & & Type 2 & Type 3 & Type 4 & Type 5 & Type 6 \\
\hline Objects & Hoarding & Hoarding & Hoarding & No hoarding & Hoarding & No hoarding \\
\hline Body & Self-neglect & Self-neglect & No self-neglect & Self-neglect & No self-neglect & Self-neglect \\
\hline Social relationship & $\begin{array}{c}\text { Social } \\
\text { withdrawal }\end{array}$ & $\begin{array}{c}\text { No social } \\
\text { withdrawal }\end{array}$ & $\begin{array}{c}\text { Social } \\
\text { withdrawal }\end{array}$ & $\begin{array}{c}\text { Social } \\
\text { withdrawal }\end{array}$ & $\begin{array}{c}\text { No social } \\
\text { withdrawal }\end{array}$ & $\begin{array}{c}\text { No social } \\
\text { withdrawal }\end{array}$ \\
\hline $\mathrm{n}=50$ & $\mathrm{n}=16$ & $\mathrm{n}=12$ & $\mathrm{n}=10$ & $\mathrm{n}=1$ & $\mathrm{n}=7$ & $\mathrm{n}=4$ \\
\hline
\end{tabular}

Table 2

Diogenes syndromes with and without associated diseases

\begin{tabular}{|c|c|c|c|c|}
\hline & $\begin{array}{l}\text { All Diogenes } \\
(n=50)\end{array}$ & $\begin{array}{l}\text { Diogenes without an } \\
\text { associated disease } \\
(\mathrm{n}=23) \mathrm{a}\end{array}$ & $\begin{array}{l}\text { Diogenes with an } \\
\text { associated disease } \\
(n=27)\end{array}$ & $\begin{array}{l}\text { Adjustedb Wald } \\
\text { OR }(95 \% \text { CI })\end{array}$ \\
\hline \multicolumn{5}{|l|}{ Socio-demographic data } \\
\hline \multicolumn{5}{|l|}{ Age (years) } \\
\hline $50-74$ & $18(36 \%)$ & $11(47.8 \%)$ & $7(25.9 \%)$ & 1.00 \\
\hline$\geq 75$ & $32(64 \%)$ & $12(52.2 \%)$ & $20(74.1 \%)$ & $2.95(0.84-10.3)$ \\
\hline \multicolumn{5}{|l|}{ Gender } \\
\hline Male & $24(48 \%)$ & $12(52.2 \%)$ & $12(44.4 \%)$ & 1.00 \\
\hline Female & $26(52 \%)$ & $11(47.8 \%)$ & $15(55.6 \%)$ & $1.44(0.45-4.58)$ \\
\hline \multicolumn{5}{|l|}{ Children } \\
\hline No & $34(68 \%)$ & $18(78.3 \%)$ & $16(59.3 \%)$ & 1.00 \\
\hline Yes & $16(32 \%)$ & $5(21.7 \%)$ & $11(40.7 \%)$ & $1.41(0.7-9.16)$ \\
\hline \multicolumn{5}{|l|}{ Care Giver } \\
\hline No & $27(54 \%)$ & $12(52.2 \%)$ & $15(55.6 \%)$ & 1.00 \\
\hline Yes & $23(46 \%)$ & $11(47.8 \%)$ & $12(44.4 \%)$ & $0.69(0.21-2.29)$ \\
\hline \multicolumn{5}{|c|}{ Neurocognitive assessment and diagnosis } \\
\hline \multicolumn{5}{|l|}{ Mini Mental Status } \\
\hline$\geq 21$ & $40(80 \%)$ & $22(95.7 \%)$ & $18(66.7 \%)$ & 1.00 \\
\hline $5-20$ & $10(20 \%)$ & $1(4.3 \%)$ & $9(33.3 \%)$ & $9.88(1.08-90.3)$ * \\
\hline \multicolumn{5}{|c|}{ Global Deterioration Scale } \\
\hline $1-3$ & $36(72 \%)$ & $23(100 \%)$ & $13(48.1 \%)$ & 1.00 \\
\hline $4-7$ & $14(28 \%)$ & $0(0 \%)$ & $14(51.9 \%)$ & na \\
\hline \multicolumn{5}{|c|}{ Fronto-temporal Behavioral Scale } \\
\hline $0-2$ & $25(50 \%)$ & $17(73.9 \%)$ & $8(29.6 \%)$ & 1.00 \\
\hline $3-4$ & $25(50 \%)$ & $6(26.1 \%)$ & $19(70.4 \%)$ & $13.8(2.69-70.7)$ ** \\
\hline \multicolumn{5}{|l|}{ Life history } \\
\hline Life history missing & $13(26 \%)$ & $1(4.3 \%)$ & $12(44.4 \%)$ & 1.00 \\
\hline Life history collected & $37(74 \%)$ & $22(95.7 \%)$ & $15(55.6 \%)$ & $19.2(2.1-171.3)$ ** \\
\hline \multicolumn{5}{|c|}{ Traumatic life event during childhood } \\
\hline No & $6(12 \%)$ & $4(66.7 \%)$ & $2(33.3 \%)$ & 1.00 \\
\hline Yes & $31(62 \%)$ & $18(58.1 \%)$ & $13(41.9 \%)$ & $0.25(0.07-0.89)$ * \\
\hline
\end{tabular}

Data are number (\%). a. Percentages are the proportion of the total number of subjects in each subgroup. b. Adjusted for Age, Gender, Children and Help. * $\mathrm{p}<.05$. ${ }^{* *} \mathrm{p}<.01$ 


\section{Similarities and differences between subjects with or without an associated disease}

Socio-demographic characteristics. Multiple logistic regression analysis (Table 2) revealed that Diogenes subjects with an associated disease did not differ significantly from those without an associated disease.

Neurocognitive assessment. The mean MMS total score of the sample was $23.3 \pm 7.0$ (range $5-30$ ), and 10 subjects had a score lower than 21. Multiple logistic regression analysis revealed that the proportion of subjects with a low MMS score was significantly higher in those with an associated disease than in those without an associated disease. A significant difference in cognition was found between Diogenes subjects with an associated disease and those without. The GDS score was less than 4/7 (no deficit or a slight deficit) for all Diogenes subjects without an associated disease. The FBS score was low $(<3)$ for half of the subjects. The proportion of Diogenes subjects presenting a high score was higher in those with an associated disease than in those without.

Life history and traumatic life event during childhood. Recalling their childhood history was possible in 37 of 50 cases, significantly more often in Diogenes subjects without an associated disease. This history was missing for one Diogenes subject without an associated disease and for 12 with an associated disorder. A traumatic life event during childhood was present among 31 of these 37 life histories, and significantly more frequent among Diogenes subjects without an associated disease (see Table 2).

\section{Discussion}

Our results are in favor of maintaining the appellation "Diogenes syndrome", which embraces the entirety of the diverse situations reported to the authorities, social services and medical networks. The use of "Diogenes syndrome" is also helpful when social workers or physicians have to discuss these clinical situations. Moreover, this appellation does not appear as a judgment for the subject and facilitates contact because it refers to ancient Greece and to a valuable philosophy of life.

Clark's decision to choose the name "Diogenes syndrome" for subjects who can live as hoarders or as ascetics without any objects relied upon the absence of shame. This choice was also perhaps made under the influence of a psychodynamic concept according to which opposite symptoms could be considered clues to one and the same problem. Beyond the plasticity of symptoms during one's lifespan, a symptom can be replaced by the opposite one. This paradox is illustrated by the life stories of several celebrities, such as Howard Hughes, Edith Bouvier Beale or the Coyller brothers. Over decades, they move from elegant houses to squalor with hoarding, from a well-groomed appearance to gross self-neglect, from the social elite to social withdrawal.
This prospective study provides evidence of the existence of different clinical types of Diogenes syndrome. Interestingly, hoarding is both the most frequent and the least alerting symptom. However, $10 \%$ of our subjects did not present hoarding. Putting hoarding as a core and mandatory symptom, or even a DSM5 category (23), leads to ignoring or misclassifying these subjects who do not hoard (19). Our results also show that alerting symptoms are more often social than medical (24).

In our sample, almost half the situations remained social ones as no diseases were found to be associated with the Diogenes syndrome.

Our results about childhood histories show that a traumatic life event during childhood could be a risk factor for all Diogenes syndromes although most often present among subjects without an associated disease. To investigate this hypothesis of the role of a traumatic life event during childhood, further studies with less reluctant Diogenes subjects should include a childhood trauma scale.

Practical applications. These situations require time, an interdisciplinary approach $(25,26)$ and coordinated investigations by a medico-social team.

As supported by the present study, all subjects with a Diogenes syndrome do not always have an associated disease. Thus, a mandatory first step is the establishment of a diagnosis. A patient with a diagnosis of psychosis will be treated by the psychiatric network, whereas a patient with a diagnosis of dementia will be treated by the geriatric network.

The most difficult situations for social workers are those that remain a "grey area" (27) when no diagnosis has been made: social workers have to provide care without any medical support. For these subjects, with no medical diagnosis, the investigation of childhood history could be used as a guide, to provide an adjusted social support with possible improvement (28).

Study's limitations. These pertain to ethical and methodological considerations. The lack of large prospective studies of these subjects is related to their social behavior. Most of them are reluctant to open their doors. Most subjects with Diogenes syndrome are unable to sign and sometimes to understand the information note. The number of written consents obtained here reflects this reality. These medical and social conditions, sometimes associated with a high level of risk and burden for the neighbors and the subjects (including eviction), require prospective longitudinal [29] and case-control studies with an exploration of life history including childhood (30).

Funding Sources: This study received a Grant from the Social Action Direction for Health and Childhood (Direction de l'Action Sociale, de l'Enfance et de la Santé). DASES, 94-96 Quai de la Rapée, 75012 Paris, France.

\section{Conflict of interest: Authors declare no conflict of interest.}

Ethical standards: The Ethical standard for these non interventional prospective study " current care », require the participants to sign an information note for agreement. 


\section{References}

1. Clark A, Mankikar G, Gray I. Diogenes syndrome. A clinical study of gross self-neglect in old age. Lancet 1975;15:366-8

2. Dupré E. Les mendiants thésauriseurs. In: Pathologie de l'imagination et de l'émotivité. Payot, Paris,1925;pp 429-44

3. Navia LE. Diogenes of Sinope. The Man in the Tub. Greenwood Press, Westport

4. Flannery GR, Rolland JM, Nairn RC. Letter: Diogenes syndrome. Lancet 1975;1, 7909:750-1

5. Reiffler B. Diogenes syndrome: of omelettes and souffles. JAGS 1996;44:1484-5

6. Marcos M, Gomez-Pellin MdLC. A tale of a misnamed eponym: Diogenes syndrome. Int J Geriatr Psychiatry 2008;23 (9):990-1

7. Macmillan D. Psychiatric aspects of social breakdown in the elderly. R Soc Health J 1957;77 (11):830-6

8. Gruenberg EM. The social breakdown syndrome - some origins. Am J Psychiatry 1967;123 (12):1481-9

9. Radebaugh TS, Hooper FJ, Gruenberg EM. The Social Breakdown syndrome in the elderly population living in the community: the Helping Study. Br J Psychiatry 1987;151:341-6

10. Greenberg D, Witztum E, Levy A. Hoarding as a psychiatric symptom. J Clin Psychiatry 1990;51 (10):417-21

11. Saldarriaga-Cantillo A, Rivas Nieto JC. Noah Syndrome: A Variant of Diogenes Syndrome Accompanied by Animal Hoarding Practices. J Elder Abuse Negl 2014;27 (3):270-5. doi: 10.1080/08946566.2014.978518

12. Cole AJ, Gillett TP . A case of senile self-neglect in a married couple: “Diogenes à deux". Int J Geriatr Psychiatry 1992;7:839-41

13. Abrams RC, Lachs M, McAvay G, Keohane DJ, Bruce ML. Predictors of selfneglect in community-dwelling elders. Am J Psychiatry 2002;159 (10):1724-30. doi: 10.1176 / appi.ajp.159.10.1724

14. Burnett J, Dyer CB, Halphen JM, Achenbaum WA, Green CE, Booker JG, Diamond PM . Four subtypes of self-neglect in older adults: results of a latent class analysis. J Am Geriatr Soc 2014;62 (6): 1127-32. doi: 10.1111/jgs.12832

15. Halliday G, Banerjee S, Philpot M, Macdonald A. Community study of people who live in a squalor. Lancet 2000;355:882-6

16. Lavigne B, Hamdan M, Faure B, Merveille H, Pareaud M, Tallon E, Bouthier
A, Clément JP, Calvet B. Syndrome de Diogène et Hoarding disorder: une même entité? Encéphale 2016;42 (5): 421-425. doi: 10.1016/j.encep.2016.02.010

17. Hanon C, Pinquier C, Gaddour N, Said S, Mathis D, Péllerin J. Diogenes syndrome: a transnosographic approach. Encéphale 2004;30 (4): 315-22

18. Monfort J, Hugonot-Diener L, Devouche E, Wong C, Péan I. Le syndrome de Diogène et les situations apparentées d'auto-excluson sociale. Enquête descriptive. Psychologie et neuropsychiatrie du vieillissement 2010;8 (2):14153. doi: 10.1684 / pnv.2010.0215

19. Hurley M, Scallan E, Johnson H, De La Harpe D. Adult service refusers in the greater Dublin area. Ir Med J 2000;93 (7): 208-11

20. Kalafat M, Hugonot-Diener L, Poitrenaud J. Etalonnage français du MMS version GRECO. Rev de Neuropsychol 2003;13 (2): 209-36

21. Reisberg B, Ferris SH, de Leon MJ, Crook T. The Global Deterioration Scale for assessment of primary degenerative dementia. Am J Psychiatry 1982;139 (9):1136-9

22. Lebert F, Pasquier F, Souliez L, Petit H. Fronto-temporal behavioral scale. Alzheimer Dis Assoc Disord 1998;12 (4): 335-9

23. American Psychiatric Association. Diagnostic and statistical manual of mental disorders, 5th edn. American Psychiatric Press, Arlington VA, 2013

24. Furtos J. De la précarité sociale à l'auto-exclusion. Editions Rue d'Ulm, Paris, 2009

25. Connolly MT. Elder self-neglect and the justice system: an essay from an interdisciplinary perspective. J Am Geriatr Soc 2008;56:S244-52. doi: 10.1111/j.1532-5415.2008.01976.x

26. Beggah-Alioua S, Berger J, Cheseaux M. Interdisciplinary care for a patient suffering from Diogenes syndrome. Revue médicale Suisse 10 (436): 1420-3

27. Gunstone S. Risk assessment and management of patients with self-neglect: a 'grey area' for mental health workers. J Psychiatr Ment Health Nurs 2003;10 (3): 287-96.

28. Waserman JE, Hategan A, Bourgeois JA. Harnessing neuroplasticity in Diogenes syndrome: A proposed mechanism to explain clinical improvement. Gen Hosp Psychiatry 2014;36 (6): 761. doi: 10.1016/j. genhosppsych.2014.06.013

29. Dyer CB, Franzini L, Watson M, Sanchez L, Prati L, Mitchell S, Wallace R, Pickens S, Babinet R. Future Research: a prospective longitudinal study of elder self-neglect. JAGS 2008;56:S261-S5.

30. Saporta JA, Gans JS. Taking a history of childhood trauma in psychotherapy: achieving an optimal approach. J Psychother Pract Res 1995;4 (3): 194-204. 